\title{
Applying food frequency questionnaire to evaluate the dietary pattern and life style on women with breast cancer
}

\author{
Huda H. Alabbody * \\ Ban S. Al- Nasiry ** \\ Khalida H. Kadhim ***
}

\author{
MSc (Internal and Preventive Vet. Med.) \\ MSc (Zoonotic Diseases Vet. Med) \\ Diploma of Higher Health Institute
}

J Fac Med Baghdad 2018; Vol.60, No.2 Receive Feb. 2018 Accepted Sep. 2018

Background: Breast cancer is the most common cancer among women and ranked number two after lung cancer in the world. According to the World Health Organization, breast cancer accounts for $22.9 \%$ among cancers in women in 2012.

Objective: This study was designed to evaluate the dietary pattern particularly dairy products consumption and the role of lifestyle on women with breast cancer in Baghdad city and its suburbs.

Subjects and Methods: The study was conducted on 100 women with breast cancer, as a case group, compared with a control group comprised of 100 healthy women. Demographic data were collected from both groups. A food frequency questionnaire was used of 33 items of foods for reporting the dietary pattern and modes of life style of the participants. The statistical Chi-square test / SPSS V.22 was used to analyze the data.

Results: Our data show that $71 \%$ of the women in the two groups were found to be overweight with body mass index (BMI 25-29.9). 90\% of obese women represented in case group (BMI $\geq 30$ ), while $82 \%$ of normal weight women (BMI 18.5-24.9) were in control group. Approximately $61 \%$ of women in both groups were in post-menopausal age. Intake of high fatty dairy products by the participants showed a statistically significant increase in breast cancer risk $(\mathrm{OR}=1.625$, CIs 95\%=0.686-3.847). Consumption of vegetables and fruits was significantly lower $(\mathrm{P}<0.01)$ in case group than in the control group. Furthermore, roughly $68 \%$ women in the case group used to smoke cigarettes. In addition, lack or decreased regular physical exercises (never with $\geq 1$ practice per wk) was statistically significant $(\mathrm{OR}=44$. 809; $\mathrm{CIs}=5.889-340.963)$. Other parameters, including long period of breastfeeding, early age at first birth and consumption of white meat, beans and eggs were all reported to have significance. On the other hand, there was no correlation with the marital status, occupation, living area, class of dairy products, and passive smoking.

Conclusion: Unhealthy dietary habits especially high-fat dairy intake and wrong lifestyle may be risk factors and predispose Iraqi women for breast cancer development. Therefore, eating healthy food and following correct lifestyle are highly recommended as a suitable program for the prevention of breast cancer.

Keywords: Breast cancer, Dairy products, Dietary patterns, lifestyle, Food frequency questionnaire (FFQ)

Introduction:

Breast cancer is the most common cancer among women and the second most frequent cancer in the world after lung cancer. In 2012, Breast cancer formed about $22 \%$ of cancers in women's cancers according to the World Health Organization. Globally, nearly 1.7 million women were diagnosed with breast cancer and 212 women $\backslash 1000,000$ died due to this condition during that year (1). In Iraq, breast cancer is currently the second leading cause of mortality among women after cardiovascular diseases forming $23 \%$ of cancer related deaths, and the first type of cancer suffered by Iraqi women as documented in the Iraqi Cancer Registry occurring

* The Iraqi National Cancer Research Center,
University of Baghdad/
hudaalabbody@gmail.com
** College of Veterinary Medicine, Zoonotic
Diseases, University of Baghdad
***Intensive care unit, Imamein Kadhimein Medical
City.

in younger women in contrast to western societies.(2) Local studies have shown that morbidity and mortality rates of breast cancer is a real problem due to the physical and psychological distress related to chemotherapy and other forms of treatment $(3,4)$. A healthy diet is important for health promotion and disease prevention, especially chronic diseases including cardiovascular diseases (CVD) and diabetes. Healthy diet is associated with lowering the risk of some cancers, including breast cancer. The study of food elements and dietary patterns in a nation is of big impact because they are affected by environmental, cultural, social, health, genetic, lifestyle and economic factors (5). Although many studies have investigated the relationship between breast cancer and food (including vegetables, fruits, dairy, meat, soy and fat) this has not been evidenced (6). Results of some recent studies reveal the association of soy proteins and green tea on the reduction of breast cancer risk ( 7 , 8 ), while the intake of red meat, high-fat, salty or processed foods and lack of fresh vegetables or fruit 
have been considered as important risk factors for breast cancer (9). It is worth mentioning that the incidence of breast cancer in Japanese women is low, in spite of high fat intake, which might be attributed to the intake of sea food fat with omega 3 oils (10). Dietary patterns can be modified through nutritional advice. The United States Department of Agriculture (USDA) advises adults to consume three meals of dairy foods per day. Importance of disease prevention and health promotion is one of the main duties of nurses among other health professionals. Nurses can help in alleviating the risk of breast cancer through identifying risk factors and providing health education for women with or without breast cancer $(6,11)$. This study was designed to evaluate the consumption of dairy products, other diets and lifestyle behaviors that are associated with increased risk of breast cancer in Iraqi women in Baghdad city and its suburbs.

\section{Subject and Methods:}

Methodology: Study design: Case-control study. Consent was obtained from all the participants before conducting the questionnaire. Study Sample: The study included two random groups, 100 women with breast cancer formed the case group and another 100 apparently healthy women without breast cancer formed the control group with a negative family history of breast cancer among first and second degree relatives. Both groups were 35-70 years old, lived $\geq 5$ years in Baghdad city or its suburb. The case group was diagnosed with breast cancer no more than 6 months before the interview. The questionnaire was completed before their chemotherapy or radiotherapy sessions. Interviews were conducted after the consent of the patient was obtained. The control group consisted of women working in the hospital or accompanying the patients. The interviews were conducted from 1 June - 31 August 2017. Place of interviewing: The questionnaire process was conducted at Imamein Kadhemin Medical City Hospital; the cases were interviewed in the Ward of Tumors and Blood Diseases in the hospital. Instrument: the study involved: Calculation of body mass index (BMI) Height and weight were measured using folding rule beech and a classic balance (KUBOTA mark, Japan). The BMI was calculated through dividing weight by the square of height $\left(\mathrm{kg} / \mathrm{m}^{2}\right)$. Overweight was defined as a BMI of $25-29.9 \mathrm{~kg} / \mathrm{m}^{2}$ and obese was defined as a BMI $\geq 30 \mathrm{~kg} / \mathrm{m}^{2}$, while the normal weight was defined as a BMI of $18.5-24.9 \mathrm{~kg} / \mathrm{m}^{2}$. Performing a questionnaire, which included two parts: Part 1: Demographic questionnaire: Information collected from each participant included: age, marital status, number of births, period of breastfeeding, address (urban or rural), menstrual and reproductive history, use of exogenous hormones, taking contraceptives, active and passive smoking, physical activity and finally previous illnesses. Smoking was defined as taking at least one cigarette per day for more than six continuous months. Physical activity was defined as practicing physical exercise at least 20-30 minutes daily or 150 minutes per week for more than six continuous months. Relevant medical information including the diagnosis were obtained from the hospital medical records. Part 2: Food Frequency Questionnaire (FFQ): utilized a list of 33 food items (table 1) including the routine diet of women during the previous year in the control group and the last year before mastectomy in the case group. Most of the listed items related to dairy products such as whole milk, low fat milk, skimmed milk, and other foods such as meat, beans, fruits and vegetables. The food questionnaire was considered in terms of frequency as (daily, 4-5 times weekly, 2-3 times weekly, once weekly, seldom, and never) seldom mean $\geq$ two weeks. The portion sizes of the foods were specified according the US Department of Agriculture portion sizes (12) (e.g. Apple: one medium, bread: one slice, milk: one cup). When the US Department of Agriculture portion sizes were not applicable, household measures were used (e.g. Yogurt one cup or cheese one piece (100 grams), beans: one tablespoon, chicken meat: one wing or leg.

Table 1: The 33 food items listed in the FFQ

\begin{tabular}{llll}
\hline Item & Type & Varieties & Portion sizes of consuming foods \\
\hline \multirow{2}{*}{$\begin{array}{l}\text { Dairy } \\
\text { products }\end{array}$} & Milk & $\begin{array}{l}\text { Full fat, low fat, skimmed, condensed, powder, } \\
\text { added to tea or coffee, added to the fruit }\end{array}$ & One cup (200 ml) Every item \\
\cline { 2 - 4 } & Yogurt & $\begin{array}{l}\text { Full Fat, low fat, skimmed, added to fruit or } \\
\text { vegetables, added to garlic }\end{array}$ & One cup (200 ml) Every item \\
\cline { 2 - 4 } & Cheese & Full fat, low fat, skimmed & One piece (100 grams) every item \\
\cline { 2 - 4 } & Butter & Absolute, Ice cream, & One piece (100 grams) \\
\cline { 2 - 4 } Other & Cream & Cggs & One piece (100 grams) every item \\
\cline { 2 - 4 } & Bread & Tea and coffee & One chicken egg \\
\cline { 2 - 4 } & Beverages & White meats (Fish and chicken) and Red meats & One cup (200 ml) \\
\cline { 2 - 4 } & Animal foods & Chicken meat: one wing or leg, one steak: (100 grams) \\
\cline { 2 - 4 } & Plant foods & Fresh fruits, vegetables, and beans & I.e. : apple: one medium, beans: one tablespoon \\
\hline
\end{tabular}

Statistics :The data were analyzed in SPSS software version 22 for comparison between variables, the chi-square test was used in a level of significance lower of 0.01 and odd ratio values in $95 \%$ confidence intervals (CIs)

\section{Results:}

Figure 1 shows the socio-demographic and other variables of the two groups. In the two groups, the means age were 52 years with a range of $(35-70)$ 
with standard deviation \pm 10 years, with most of the women being postmenopausal. The majority was from urban areas and married, overweight or obese. Obesity was mainly seen in the case group, with most women never practising physical exercise in both groups. However, $26 \%$ of control group were practicing once or more weekly. The mean of age at first birth was higher in the case group compared to the control group, with a longer period of breast feeding in the control group, (Figure 1).

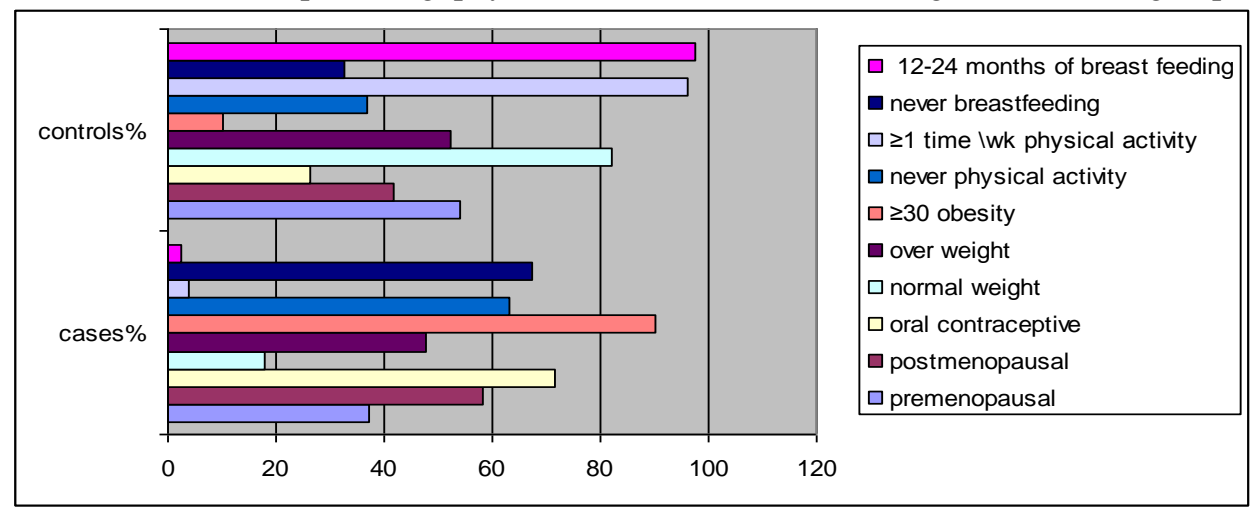

Figure 1: Essential demographic data and clinical characteristics of the participants

Table 2 shows the most frequently consumed foods by women in the two groups. There were similar values in most nutrient items except low fat milk, when $12 \%$ of all women in both groups had consumed low fat milk, but the largest number of them was from the control group $95.8 \%$.

Table 2: Consumption of favorite foods among the study women

\begin{tabular}{|c|c|c|c|c|c|c|c|c|}
\hline \multirow{2}{*}{ The favorite food } & \multicolumn{2}{|l|}{ Case } & \multicolumn{2}{|c|}{ Control } & \multirow[t]{2}{*}{ Total } & \multirow{2}{*}{$X^{2}$} & \multirow{2}{*}{ df } & \multirow{2}{*}{$p$} \\
\hline & No. & $(\%)$ & No. & $(\%)$ & & & & \\
\hline Milk & 17 & 47.2 & 19 & 52.8 & 36 & \multirow{6}{*}{4.010} & \multirow{6}{*}{5} & \multirow{6}{*}{.548} \\
\hline Yogurt & 22 & 48.8 & 23 & 51.2 & 45 & & & \\
\hline Cheese & 12 & 42.8 & 16 & 57.2 & 28 & & & \\
\hline Butter & 15 & 45.4 & 18 & 54.6 & 33 & & & \\
\hline Butter fat & 18 & 66.6 & 9 & 33.4 & 27 & & & \\
\hline Cream & 16 & 51.6 & 15 & 48.4 & 31 & & & \\
\hline Full fat milk & 92 & 56.7 & 70 & 55.3 & 162 & \multirow{3}{*}{35.294} & \multirow{3}{*}{2} & \multirow{3}{*}{$.001 *$} \\
\hline Low f. m. & 1 & 4.2 & 23 & 95.8 & $24(12 \%)$ & & & \\
\hline Skimmed f. m. & 1 & 12.5 & 7 & 87.5 & 8 & & & \\
\hline Plant foods & 48 & 46.2 & 56 & 53.8 & 104 & \multirow{2}{*}{1.282} & \multirow{2}{*}{1} & \multirow{2}{*}{.258} \\
\hline Animal foods & 52 & 54.1 & 44 & 45.9 & 96 & & & \\
\hline
\end{tabular}

* has a statistical significant value

Table 3 shows the Frequency of milk types' consumption, according to lipids level: $62 \%$ of the control group and $38 \%$ of the case group were never taking full fat milk. On the other hand $84.3 \%$ of the control group and $15.7 \%$ of case group were taken skimmed milk daily.

Table 3: Frequency of milk's types intake by the study groups

\begin{tabular}{|c|c|c|c|c|c|c|c|c|c|}
\hline \multirow{2}{*}{ Food intake } & \multirow{2}{*}{ Frequency } & \multicolumn{2}{|c|}{ Case } & \multicolumn{2}{|c|}{ Control } & \multirow{2}{*}{ Total } & \multirow{2}{*}{$x 2$} & \multirow{2}{*}{ df } & \multirow{2}{*}{$p$} \\
\hline & & No. & $\%$ & No. & $\%$ & & & & \\
\hline \multirow{6}{*}{ Full fat milk } & 1 in week & 20 & 83.3 & 4 & 16.7 & 24 & \multirow{6}{*}{41.116} & \multirow{6}{*}{5} & \multirow{6}{*}{$.0001 *$} \\
\hline & $2-4$ in week & 17 & 65.3 & 9 & 35.7 & 26 & & & \\
\hline & $5-6$ in week & 14 & 50 & 14 & 50 & 28 & & & \\
\hline & Daily & 14 & 93.3 & 1 & 6.7 & 15 & & & \\
\hline & Seldom & 3 & 13 & 20 & 87 & 23 & & & \\
\hline & Never & 32 & 38 & 52 & 62 & 84 & & & \\
\hline \multirow{6}{*}{ Low fat milk } & 1 in week & 14 & 63.6 & 8 & 36.4 & 22 & \multirow{6}{*}{80.789} & \multirow{6}{*}{9} & \multirow{6}{*}{$.0001 *$} \\
\hline & $2-4$ in week & 26 & 92.8 & 2 & 7.2 & 28 & & & \\
\hline & $5-6$ in week & 1 & 50 & 1 & 50 & 2 & & & \\
\hline & Daily & 12 & 46.1 & 14 & 53.9 & 26 & & & \\
\hline & Seldom & 9 & 42.8 & 12 & 57.2 & 21 & & & \\
\hline & Never & 38 & 37.6 & 63 & 62.4 & 101 & & & \\
\hline \multirow{6}{*}{ Skimmed fat milk } & 1 in week & 39 & 73.5 & 14 & 26.5 & 53 & \multirow{6}{*}{83.780} & \multirow{6}{*}{4} & \multirow{6}{*}{$.0001 *$} \\
\hline & $2-4$ in week & 1 & 20 & 4 & 80 & 5 & & & \\
\hline & $5-6$ in week & 1 & 20 & 4 & 80 & 5 & & & \\
\hline & Daily & 9 & 15.7 & 48 & 84.3 & 57 & & & \\
\hline & Seldom & 5 & 38.4 & 8 & 61.6 & 13 & & & \\
\hline & Never & 45 & 70.3 & 22 & 29.7 & 64 & & & \\
\hline
\end{tabular}

* had a statistical significant value 
Figure 2 shows the frequency of different food items intake which were included in this study in addition to dairy products. As an example; red meat consumption was reported by $6 \%$ of cases and $94 \%$ of controls on a seldom basis while daily basis by $91 \%$ of cases and $9 \%$ of controls. Fish consumption was reported by $76 \%$ of cases and $24 \%$ of controls on a seldom basis; while $27 \%$ and $73 \%$ had taken fish a 2-4 times basis in the case and control groups respectively. Also the figure shows the frequency of consumption of fruits, vegetables and beans; $92 \%$ of the controls and $8 \%$ of the cases had taken the fruits on daily basis , $72 \%$ of controls and $28 \%$ of cases had taken vegetable daily while; $75 \%$ of cases and $25 \%$ of controls have taken vegetable on seldom basis. On the other hand, $90 \%$ of cases and $10 \%$ of controls have taken Beans on seldom basis, (Figure 2)

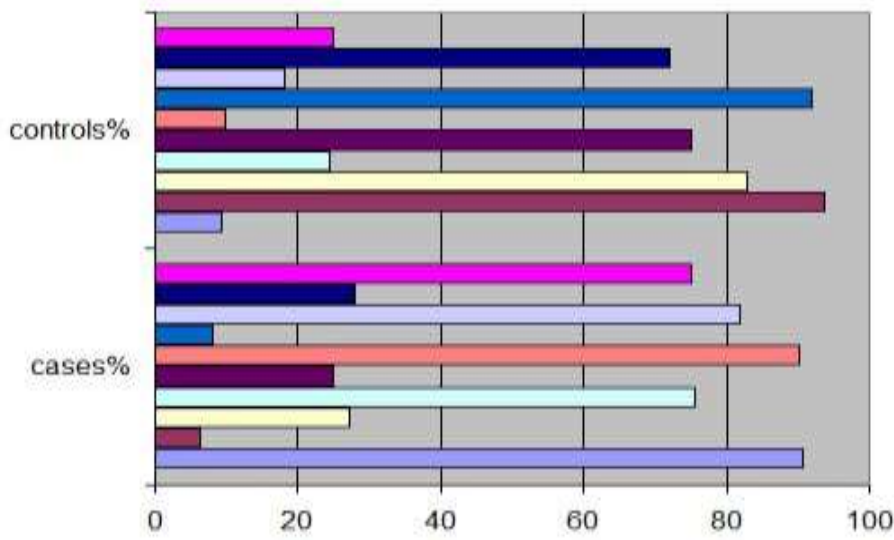

Figure 2: The frequency of foods intake by women groups
Table 4 shows the value of odds ratio (OR) in $95 \%$ confidence intervals (CIs) for Some variables, for example, a reduction in breast cancer risk $(\mathrm{OR}=44$, CI $95 \%=5.889-340.963)$ was observed among active women who practiced exercises $(1 \geq$ in a week) compared to never practiced women. The use of contraceptive pills revealed breast cancer risk $(\mathrm{OR}=4.623$, CI 95\%=2.507-8.526). Postmenopausal women showed a high correlation with breast cancer risk $(\mathrm{OR}=2.352$, CI 95\%=1.313-4.215). Likewise, the consumption of full fat milk daily had a statistically corresponding association with breast cancer risk $(\mathrm{OR}=1.6$, CI $95 \%=0.686-3.847)$ in comparison never with daily consumption. This table also shows logistic regression of the vegetable $\mathrm{OR}=0.02(0.003-0.16)$, chicken $\mathrm{OR}=0.173(0.019$ $1.544)$ and beans $\mathrm{OR}=0.036(0.011-0.116)$.

Table 4: Estimated regression coefficients of variables with breast cancer risk

\begin{tabular}{|c|c|c|c|c|}
\hline \multicolumn{2}{|c|}{ Variables } & Frequency & $X^{2}: \mathrm{df}:$ & Odds ratio (CI 95\%) \\
\hline \multirow{5}{*}{ 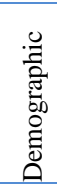 } & BMI & Obesity \Normal weight & $31.025: 2: .0001$ & $0.092(0.38-0.220)$ \\
\hline & Menopause & Postmenopausal $\backslash$ Premenopausal & $8.407: 1: .004$ & $2.352(1.313-4.215)$ \\
\hline & Months of breast feeding & Never $12-24$ months & $152.556: 4: .0001$ & $0.006(0.001-0.051)$ \\
\hline & Physical activity & Never $\backslash \geq 1$ time in wk & $36.423: 2: .0001$ & $44.809(5.889-340.963)^{*}$ \\
\hline & Used oral contraceptive & Never\Ever & $3.089: 1: .079$ & $4.623(2.507-8.526)^{*}$ \\
\hline \multirow{5}{*}{$\stackrel{\breve{\omega}}{\square}$} & Full fat milk & Daily $\backslash$ Never & $41.116: 5: .0001$ & $1.625(0.686-3.847)$ \\
\hline & Skimmed fat milk & Never\ Daily & $83.780: 4: .0001$ & $0.092(0.038-0.220)$ \\
\hline & Vegetables & Never\ Daily & $200.000: 4: .0001$ & $0.022(0.003-0.168)$ \\
\hline & Chicken & Never\ Daily & $80.730: 5: .0001$ & $0.173(0.019-1.544)$ \\
\hline & Beans & Seldom $\backslash 2-4$ in week & $81.060: 6: .0001$ & $0.036(0.011-0.116)$ \\
\hline
\end{tabular}

\section{Discussion:}

This case-control study suggested that various dietary and non-dietary factors were associated with increased risk for breast cancer, such as increased BMI. Many studies agree with this study strongly and suggested the obesity represented by BMI increases is one of the risk factors for breast cancer as a result to increased levels of circulating steroid hormones like estrogen $(13,14)$. Many behavioural

choices during life are likely to enhance the risk of developing breast cancer. There is strong scientific evidence that not having children or having them $\square$ Seldom vegetable intake

- Daily vegetable intake

$\square$ Seldom fruit intake

口 Daily fruit intake

口 Seldom beans intake

- 2-4 times in week beans intake $\square$ Seldom fish intake

口2-4 times in week fish intake

$\square$ Seldom red meat intake

$\square$ Daily red meat intake after 30 years old, avoiding breast feeding, prolonged use of the contraceptive pill and smoking increase the risk of developing mammary tumours $(15,16)$. In this study the women with prolonged use of the contraceptive pill $(72 \%)$ were in the case group, while $97 \%$ of breastfeeding women were in the control group. Breastfeeding decreases hormones like oestrogen, exfoliates breast tissue and the breast tissue goes through a healthy controlled cell death after termination of lactation. This will eliminate cells with division errors during, which may potentially lead to breast cancer. $(17,18)$ Other aspects of lifestyle have also been investigated by many researchers, like the physical activity, which 
associated with lower risk of invasive breast cancer which conform the findings in this study. A considerable number of studies have been conducted worldwide on physical activity and breast cancer risk, as in one study an average a $20-25 \%$ reduction in breast cancer risk on this practice (19). Cancer prevention guidelines of The American Cancer Society (ACS) and World Cancer Research Fund (WCRF) advise doing practical exercises for at least 150 minutes per week to avoid breast cancer. Physical activity offers a true protection in all types of breast cancers which vary in histopathology, hormone receptor status, and gene expression profile. (14) The analysis of the relationship between diet and breast cancer is still a controversial issue. In this study; the control group had higher daily consumption of fruit $72 \%$ and vegetable $92 \%$. Other studies found substances contained in vegetable foods as possible ways to prevent cancer, since a number of studies have suggested that people who eat more fruit and vegetables are less likely develop cancer. Although there is evidence to show that a diet rich in plant foods may be protective against cancer risk and provide many health benefits (20). Recently the International Agency for Research on Cancer (IARC) and (WCRF) have remarked that diet strongly influences cancer prevention, disease development, and also provide advice and recommendations for body weight management in breast cancer primary and secondary prevention [21, 22). Recent systematic reviews and case-control studies found that women who ate greater amounts of cruciferous vegetables like turnips, cauliflower and broccoli, which contain higher fiber, have linked with a lower risk of breast cancer, $5 \%$ risk reduction for every additional $10 \mathrm{~g}$ of fiber per day. Fiber may reduce risk by reducing the re-absorption of estrogen and androgens in the bowel and hence their circulating levels. Slushy fibers show the high protection during its beneficial effects on insulin sensitivity $(23,24)$. Evidence of the relationship between milk and dairy products with the risk of cancer points in different directions, thus making it difficult to draw a conclusion. This study supported protective association to the higher consumption of low-fat dairy products when in this study women who consumed skimmed milk daily had been $(84 \%)$ and who had lower consumption (seldom) of highfat dairy products had been $(87 \%)$ were in controls. The best advice towards milk, dairy products, and breast cancer prevention is to consume these foods in line with the recommendations for a healthy diet, which favours low-fat dairy products. Moreover milk or dairy consumption has been suspected of playing a role in the development of breast cancer and the hypotheses that have been put suggest increased cancer risk associated with milk consumption include high dietary fat content, contaminants in milk and hormones contained in milk such as oestrogens and IGF-1 (25). One of the main limitations in the field of nutritional science is that food and nutrients are not consumed in isolation and, from an epidemiological point of view, form a complex network of correlated influences. Therefore, it is difficult to study dietary patterns, which simultaneously reflect these exposures (26). Moreover, prospective studies are required to improve dietary assessment instruments and develop new biomarkers, particularly recovery biomarkers of dietary intake. Similarly, the stratification of breast cancer by specific characteristics should be further considered, particularly the individual metabolism, genetics, receptor status (oestrogen receptor, progesterone receptor, human epidermal growth factor receptor-2), substantial decline of ovarian hormones after menopause and other molecular classifications. It is possible that the beneficial effects of dietary exposures are restricted to subgroups of women defined by specific genetic characteristics; therefore, future studies of gene-diet interactions will have to take into account genetic polymorphism when associations between dietary exposures and breast cancer risk are analysed. In addition, most of the evidence in the literature has been obtained from studies that have evaluated diet during midlife and later, whereas the food exposures during menarche and first pregnancy like red meat and fatty meal may be more important in the development of breast cancer (27). In this study about $91 \%$ women had been eating red meat daily in cases while about $94 \%$ women had been eating them seldom in controls. Red meat consumption may significantly increase the risk of breast cancer in both premenopausal and postmenopausal women (28) while white meat and beans may be accompanied with reduced probability of breast cancer in women. In this study, the women who had eaten beans daily were about $82 \%$ in controls while the women who had seldom eaten beans were $90 \%$ in cases. Recommendations for cancer prevention on diet, nutrition, physical activity and weight management, is associated with a lower risk of developing most types of cancer, including breast cancer (29). This confirms that 'healthy diet and lifestyle' are important tools for the prevention of cancer.In conclusion, we found an inverse, independent association between the risk of breast cancer and higher consumption of fatty dairy products, independent of potential confounding variables, especially BMI and menopausal status. Moreover higher intakes of low-fat dairy products as well as lower intakes of high-fat dairy were accompanied with reduced odds of breast cancer in women. It is recommended to evaluate the relationship between dietary patterns and breast cancer in further and future studies in order to prove a stronger relationship between cause and effect. It is suggested that divide and classify the subjects in terms of menopausal status, estrogen receptor and progesterone, smoking status, and family record of breast in order to investigate their relationship with breast cancer to reveal more details. The results of this study underlines the importance of informing 
women, particularly those with a higher risk of breast cancer risk in relation to risky dietary factors. $(30,31)$

\section{Author's Contributions:}

This study was conceived, designed, analysis the results and drafting the manuscript was done by Huda H. Alabbody, output the data , contribution in analysis the results was done by Ban S. Al- Nasiry, the interview with women, fill the questionnaire and input the data in the statistical program was done by Khalida H. Kadhim

\section{References:}

1. World Cancer Report, International Agency for Research on Cancer, World Health Organization. 2014; ISBN 978-92-832-0432-9

2. Iraqi Cancer Board Results of the Iraqi Cancer Registry, 2012. Baghdad, Iraqi Cancer Registry Center, Ministry of Health, Iraq; 2015.

3 Lafta, R.; Saeed, E. and Isa, S. Risk factor of breast cancer among women. Iraqi Journal. Comm. Med., 2013: 26 (1):1-6.

4. Al-Attar WMA, Al-Abbody HH. Assessment of Performance Status on Physical and Psychological Problems Related to Chemotherapy among Patients with Cancer. KUFA J. NUR. SCI. 2017; 7 (1)56-65.

5. Karimi Z, Jessri M, Houshiar-RA, et.al. Dietary patterns and breast cancer risk among women. Public Health Nutrition 2013; 17 (5): 1098-106

6. Tahrgoraby Z, Moadaby M, and Mesbahzade B. Breast cancer is a preventable disease. J Birjand University Med Sci. 2014; 21: 126-41.

7. Shrubsole $M J, L u W$, Chen Z, et al. Drinking green tea modestly reduces breast cancer risk. J Nutr. 2009; 139: 310-16.

8. Kimiagar M, Hegazy E. Soy isoflavones and breast cancer risk. J Shahid Beheshti University Med Sci, 2010; 2, 52-8.

9. Kruk J. Association between vegetable, fruit and carbohydrate intake and breast cancer risk in relation to physical activity. Asian Pac J Cancer Prev.2014; 15: 4429-36.

10. Zheng J, Hu X, Zhao Y, et.al. Intake of fish and marine $n-3$ polyunsaturated fatty acids and risk of breast cancer: meta-analysis of data from 21 independent prospective cohort studies. BMJ. 2013;346: 1-10.

11. Safaryan M, Shogaezade M, Ghayur $M$, et al Check dietary patterns, healthy nutrition profile and traditional risk factors for cardiovascular disease in adults 35 to 65 in Mashhad. J Mashhad University Med Sci. 2013; 56: 226-35.

12. Home and Garden Bulletin. Nutrition and Your Health: Dietary Guidelines for Americans. 5th ed. Washington, DC: US Department of Agriculture; 2000: 232.

13. Munsell MF, Sprague BL, Berry DA, et.al. Body mass index and breast cancer risk according to postmenopausal estrogen-progestin use and hormone receptor status. Epidemiol Rev. 2014;36:114-36.
14. Bowes ADP, Pennington JAT, Church HN, et al. (1998) Bowes \& Church's Food Values of Portions Commonly Used. Philadelphia: Lippincott;: World Cancer Research Fund. American Institute for Cancer Research. Food, Nutrition, Physical Activity, and the Prevention of Cancer: A Global Perspective. Washington, DC: American Institute for Cancer Research.

15. Goncalves AK, Florencio GLD and Maisonnette de Atayde Silva MJ et al (2014). Effects of physical activity on breast cancer prevention: a systematic review J Phys Act Health 11 445-454 DOI: 10.1123/jpah.2011-031.

16. Jernstrom H, Lubinski J, Lynch HT, et al.(2004) Breast-feeding and the risk of breast cancer in BRCA and BRCA mutation carriers. J Natl Cancer Inst 96:1094-1098.

17. Newcomb PA, Egan KM, Titus-Ernstoff L, et al. (1999) Lactation in relation to postmenopausal breast cancer. Am J Epidemiol 150: 174-182. 17Moorman PG \& Terry PD (2004). Consumption of dairy products and the risk of breast cancer: a review of the literature. Am J Clin Nutr. 80: 5-14.

18. Valerie Beral (2002) Breast cancer and breastfeeding: Collaborative reanalysis of individual data from 47 epidemiological studies in 30 countries, including 50302 women with breast cancer and 96973 women without the disease, 360 (9328): 187-195.

19. Lynch BM, Neilson $H K$ and Friedenreich CM (2011) Physical activity and breast cancer prevention Recent Results Cancer Res 186 13-42 DOI: 10.1007/978-3-642-04231-7_2.

20. Norat T, Aune D and Chan D et al (2014) Fruits and vegetables: updating the epidemiologic evidence for the WCRF/AICR lifestyle recommendations for cancer prevention Cancer Treat Res 159 35-50 DOI: 10.1007/978-3-642-38007-5_3.

21. Research. WCRFiAwAIfC (2014) Continuous Update Project Report: Diet, Nutrition, Physical Activity, and Breast Cancer Survivors World Cancer Research Fund/American Institute for Cancer Research.

22. Research. WCRFiAwAIfC (2010) Continuous Update Project Report. Food, Nutrition, Physical Activity, and the Prevention of Breast Cancer: World Cancer Research Fund in Association/American Institute for Cancer Research. 23. Aune D, Chan DS, Greenwood DC, et al. (2012) Dietary fiber and breast cancer risk: a systematic review and meta-analysis of prospective studies. Ann Oncol. 23 :1394-1402.

24. Terry P, Wolk A, Persson I, Magnusson C. (2001). Brassica vegetables and breast cancer risk. JAMA.285(23):2975-2977.

25. Chagas CE, Rogero MM and Martini LA (2012) Evaluating the links between intake of milk/dairy products and cancer Nutr Rev 70 294-300 DOI: 10.1111/j.1753-4887.2012.00464.x PMID: 22537215 .

26. Albuquerque RC, Baltar VT and Marchioni DM (2014) Breast cancer and dietary patterns: a 
systematic review Nutr Rev 72 1-17 DOI: 10.1111/nure.12083.

27. Farvid MS, Cho E and Chen WY et al (2014) Dietary protein sources in early adulthood and breast cancer incidence: prospective cohort study BMJ 348 g3437 DOI: 10.1136/bmj.g3437 PMID: 24916719 PMCID: 4051890.

28. Taylor EF, Burley VJ, Greenwood DC, et.al. Meat consumption and risk of breast cancer in the UK Women's Cohort Study. Br J Cancer. 2007; 96(7):1139-1146.

29. Romaguera D, Vergnaud AC and Peeters PH et al (2012) Is concordance with World Cancer Research Fund/American Institute for Cancer Research guidelines for cancer prevention related to subsequent risk of cancer? Results from the EPIC study Am J Clin Nutr 96 150-163.

30. Reyhany M, Fahamy F, Moshref Sh, et.al. (2012). Its dairy and animal protein intake with breast cancer in Isfahan. J Med Educat Zanjan. 20: 45-54.

31. Harvie M, Howell A, Evans DG (2015). Can Diet and Lifestyle Prevent Breast Cancer: What Is the Evidence? American Society of Clinical Oncology.:e66-e73. 